\title{
Soil fungal communities in tea plantation after 10 years of chemical vs. integrated fertilization
}

\author{
Li-Min Wang ${ }^{1}$ 2*$^{*}$, Dong-Feng Huang ${ }^{1}$, Yu Fang ${ }^{1}$, Fei Wang ${ }^{1}$, Fang-Liang Li ${ }^{1}$,
}

and Min Liao ${ }^{2}$

\section{ABSTRACT}

Addition of livestock manures and plant residues is a feasible practice to largely mitigate soil-degradative trends by the soil-dwelling fungi. However, long-term impacts of these fertilization regimes on the fungal community are poorly documented in tea (Camellia sinensis (L.) Kuntze) plantations in subtropical areas. In this study, MiSeq sequencing approach was used to estimate the diversity and composition of fungal communities in soils treated with $10 \mathrm{yr}$ of non-fertilization control (CK), chemical fertilizers only $(\mathrm{CF})$, and integrated use of chicken manure and legume straw with chemical fertilizers (IF), respectively. We found that different fertilization treatments produced little effect on the richness and diversity of soil fungi compared to those of the controls. In addition, Ascomycota, Basidiomycota, Zygomycota, Glomeromycota, and Chytridiomycota were the five most abundant phyla in soils under different fertilization treatments. Moreover, IF resulted in the prevalence of the genera Fusarium, unclassified Microascaceae, and unclassified Ascomycota, which accounted for $30.04 \%, 18.77 \%$, and $6.92 \%$ of the total fungi, respectively. Additionally, the relative abundance of the phylum Ascomycota was positively correlated with $\mathrm{pH}$, total $\mathrm{N}(\mathrm{TN})$, soil organic $\mathrm{C}$ (SOC), soil moisture (SM) and silt (SI) contents; however, these soil physicochemical properties were negatively correlated with the relative abundance of the phylum Basidiomycota. Together, these results suggest that the changes of the fungal community structure at the genus and phylum level under IF treatment could be the result of their responses to variations of soil $\mathrm{pH}, \mathrm{SM}, \mathrm{TN}, \mathrm{SOC}$, and SI contents.

Key words: Camellia sinensis, correlation, fertilization regimes, fungal composition, fungal diversity, physicochemical properties.

${ }^{1}$ Soil and Fertilizer Institute, Fujian Academy of Agricultural Sciences, Fuzhou, Fujian 350013, China.

"Corresponding author (gb898@126.com).

${ }^{2}$ Zhejiang Provincial Key Laboratory of Subtropic Soil and Plant

Nutrition, Hangzhou, Zhejiang 310058, China.

Received: 18 June 2017

Accepted: 15 October 2017.

doi:10.4067/S0718-58392017000400355

\section{INTRODUCTION}

Tea plant (Camellia sinensis (L.) Kuntze), originated from China, is an important cash crop, covering approximately 60 countries. A tea cultivar ('Huangguanyin'), as one of the major sources of tea supply, is generally grown in southeast China where tea soils are vulnerable to erosion by water. Therefore, large amounts of chemical fertilizers have been applied in tea plantations over the past few decades in order to maximize tea yields. The excessive use of chemical fertilizers can cause serious soil degradation, with soil acidification, soil compaction and fertility loss. Consequently the efficacy of chemical fertilizers in decreasing tea yields was observed over time. Numerous studies have demonstrated that restoration of soil degradation by the addition of organic fertilizers or manures has been shown not just from various forms of fertilizers but also through improved biological activity from the addition of C (Joergensen et al., 2010; Chen et al., 2016). However, the underlying mechanisms of fertilization practices to influence soil fertility remain largely elusive, particularly the roles of these practices on soil fungi. Soil fungi played important roles in leaf litter decomposition, which in turn promoted the sustainability and productivity in soil ecosystems (Grosso et al., 2016). Considering the significant role that soil fungi play in soil productivity, it is critical to catalogue their diversity and composition.

High-throughput sequencing (HTS) offers an important tool for surveying an extremely high fungal diversity in soils, due to its high resolution. With the modern HTS technology, this can result in hundreds of thousands and even millions of sequence reads in a single run. This technology can detect taxa that are only present at low levels in the soil. Currently, the HTS technique is increasingly used mostly for soil fungi (Caporaso et al., 2010; Lin et al., 2012). Moreover, soil fungal community composition and diversity were reportedly altered over a wide range of soil factors associated with fertilizer managements (Lauber et al., 2008; Guo et al., 2015). In general, much effort should been devoted on investigating factors that affect the fungal community composition and its response to fertilizer regimes.

To date, the response of soil fungal community to fertilization regime change was still not unanimous and even conflicted (Paungfoo-Lonhienne et al., 2015; Chen et al., 2016). For example, it has been shown that the arbuscular mycorrhizal fungi (AMF) markedly increased in relative abundance with increasing levels of the organic manure (Yu et al., 2013). In contrast, longterm application of organic manure has generally been shown 
to significantly decrease AMF richness in an arable soil compared to control plots (Lin et al., 2012). These results suggest a variable response of AMF abundance to long-term fertilization, which may depend on the host plant diversity, climate conditions, and soil types (McGuire et al., 2012; Shi et al., 2014; LeBlanc et al., 2015). Thus, it is important to evaluate responses of soil fungi to different fertilization regimes in specific soils from different farming systems. Recently, much more work has primarily focused on forest soils, grassland soils (LeBlanc et al., 2015), and arable soils (Chen et al., 2016), but few studies have evaluated the responses of soil fungi to fertilizer management in subtropical tea plantations. Consequently, it is not clear how fungi respond to different fertilization treatments in this region. Meanwhile, our understanding of the edaphic factors that influenced fungal diversity and community structure in this soil is limited. Given these limitations, we hypothesized that fungal communities can respond to the changes in the soils under different treatments, and some soil physical and chemical properties may play important roles in this process. To test the hypothesis, we experimentally manipulated soil fertility by the three most representative treatments, CK, CF (treated only by chemical fertilizers, and with the lowest tea yields), and IF (treated by combined chemical/organic fertilizers, and with the highest tea yields). The experiment was designed to determine long-term impacts of partly replacing chemical fertilizers by organic fertilizers on soil fungal diversity and composition as compared to full chemical fertilization using the HTS technology. Then, we further analyzed the relationship between variations in fungal communities and changes of edaphic parameters in order to provide insight into the influencing factors in the soil for selecting suitable fertilization strategies to improve the growth of tea plant.

\section{MATERIALS AND METHODS}

\section{Field experiment and sample collection}

A randomized field study was performed at $\mathrm{Fu}$ 'an Experimental Station $\left(26^{\circ} 41^{\prime}-27^{\circ} 24^{\prime} \mathrm{N}, 119^{\circ} 23^{\prime}-119^{\circ} 51^{\prime} \mathrm{E}\right)$ in Fujian Province, China. Soil type on site is a sandy clay loam. In addition, this soil is an acidic yellow-red soil, which is widespread in the lower-to-middle mountain area in the Fujian Province of southeastern China. The surface soil $(0-20 \mathrm{~cm})$ contained $7.40 \mathrm{~g} \mathrm{~kg}^{-1}$ organic matter, 0.40 $\mathrm{g} \mathrm{kg}^{-1}$ total N (TN), $0.10 \mathrm{~g} \mathrm{~kg}^{-1}$ total P (TP), $22.40 \mathrm{~g} \mathrm{~kg}^{-1}$ total $\mathrm{K}$ (TK), $58.34 \mathrm{mg} \mathrm{kg}^{-1}$ available $\mathrm{N}$ (AN), $0.87 \mathrm{mg}$ $\mathrm{kg}^{-1}$ available $\mathrm{P}$ (AP), $77.20 \mathrm{mg} \mathrm{kg}^{-1}$ available K (AK), and had a $\mathrm{pH}$ of 5.19 at the beginning of the experiment in 2006. This region has a subtropical humid marine monsoon climate with mean annual precipitation of 1540 $\mathrm{mm}$, air temperature of $19.3^{\circ} \mathrm{C}$, and natural photoperiod of $1837 \mathrm{~h}$. Three respective types of fertilization treatments in subtropical tea plantations with three replicates were compared: non-fertilizers (CK), chemical fertilizers $(\mathrm{CF})$, and half-poultry manure plus legume residue plus halfmineral fertilizers (IF) (Table 1). These chemical and
Table 1. Fertilizer inputs of the treatments in tea plantations.

\begin{tabular}{|c|c|c|c|c|}
\hline \multirow[b]{2}{*}{ Treatments } & \multicolumn{3}{|c|}{ Chemical fertilizers } & \multirow[b]{2}{*}{ Organic matter } \\
\hline & $\mathrm{N}$ & $\mathrm{P}$ & K & \\
\hline \multicolumn{5}{|c|}{$-\mathrm{kg} \mathrm{ha}^{-1} \mathrm{yr}^{-1}-$} \\
\hline Control (CK) & 0 & 0 & 0 & 0 \\
\hline Chemical fertilizer (CF) & 208 & 68 & 56 & 0 \\
\hline Integrated fertilizer (IF) & 104 & 34 & 28 & $\begin{array}{l}5.7 \mathrm{t} \mathrm{ha}^{-1} \mathrm{yr}^{-1} \text { poultry manure } \\
\text { plus legume (Chamaecrista } \\
\text { rotundifolia) residue }\end{array}$ \\
\hline
\end{tabular}

organic fertilizers were applied in winter. The chemical fertilizers were composed of urea, mono ammonium phosphate, and potassium chloride, which were used as $\mathrm{N}, \mathrm{P}$ and $\mathrm{K}$ fertilizers, respectively. Additionally, poultry manure was made chiefly from chicken manure, which had $368.90 \mathrm{~g} \mathrm{~kg}^{-1}$ organic matter, $9.00 \mathrm{~g} \mathrm{~kg}^{-1} \mathrm{TN}, 22.90 \mathrm{~g} \mathrm{~kg}^{-1}$ $\mathrm{TP}, 5.29 \mathrm{~g} \mathrm{~kg}^{-1} \mathrm{TK}$, respectively. The legume (Chamaecrista rotundifolia [Pers.] Greene var. rotundifolia) seeds were sowed at a rate of $7.5 \mathrm{~kg} \mathrm{ha}^{-1}$ along the rows and in the interrow spacing of tea plantations in spring. After the plant fades away every winter, its mature seeds fall along the rows where they will sprout in the next spring. Nutrient composition of legume residues had TN $22.44 \mathrm{~g} \mathrm{~kg}^{-1}$, TP $1.99 \mathrm{~g} \mathrm{~kg}^{-1}$, TK $7.31 \mathrm{~g} \mathrm{~kg}^{-1}$, respectively. Surface soil samples were collected at 0-20 cm depth on wide empty spaces in between tea plants in late May 2016. For each plot $\left(13.65 \mathrm{~m}^{2}\right), 10$ soil cores were taken and mixed to one composite sample. These soil samples were kept on wet ice and shipped within $48 \mathrm{~h}$ to the laboratory. Visible plant roots and residues were removed. Half of each soil sample was then passed through a 2-mm sieve and stored at $4{ }^{\circ} \mathrm{C}$ for soil moisture analysis, or at $-80{ }^{\circ} \mathrm{C}$ for DNA extraction, respectively. The other half was air-dried at room temperature, passed through a $0.25-\mathrm{mm}$ nylon sieve for soil physicochemical analyses. Meanwhile, plant height and tea yield were recorded from all treatments.

\section{Soil physicochemical analyses}

Soil physical and chemical properties were determined with methods described by Lal (2000). Soil particle-size distribution was analyzed by the gravimetric method. Soil moisture (SM) was calculated as the difference between field moist and the oven dried ( $24 \mathrm{~h}$ drying at $105{ }^{\circ} \mathrm{C}$ ) weight. Soil organic C (SOC) was determined using the $\mathrm{K}_{2} \mathrm{Cr}_{2} \mathrm{O}_{7}$ oxidation-reduction titration technique; and TN was detected by the Kjeldahl method. AP was determined by the sodium hydrogen carbonate solution-Mo-Sb anti spectrophotometric method. Soil $\mathrm{pH}$ was measured using a glass electrode (EL20 K, Mettler-Toledo, Greifensee, Switzerland) in 1:2.5 soil:water suspension. Plant height and tea yield were also measured using a steel tape and an electronic balance, respectively.

\section{Microbial diversity analysis}

DNA extraction and PCR amplification. Fungal DNA was extracted from $0.5 \mathrm{~g}$ soil using the E.Z.N.A. Soil DNA Kit (Omega Bio-tek, Norcross, Georgia, USA) according to the 
manufacturer's protocols (Feinstein et al., 2009). The V4-V5 regions in the $18 \mathrm{~S}$ ribosomal RNA gene of the fungi were amplified by PCR $\left(95^{\circ} \mathrm{C}\right.$ for $3 \mathrm{~min}$, followed by 25 cycles at $95^{\circ} \mathrm{C}$ for $30 \mathrm{~s}, 55^{\circ} \mathrm{C}$ for $30 \mathrm{~s}$, and $72{ }^{\circ} \mathrm{C}$ for $45 \mathrm{~s}$ and a final extension at $72{ }^{\circ} \mathrm{C}$ for $10 \mathrm{~min}$ ) using primers SSU0817F 5'-barcode- TTAGCATGGAATAATRRAATAGGA-3' and 1196R 5'-TCTGGACCTGGTGAGTTTCC-3', where a barcode is an unique eight-base sequence for each sample. PCR reactions were performed in triplicate $20 \mu \mathrm{L}$ mixture containing $4 \mu \mathrm{L} 5 \times$ FastPfu Buffer, $2 \mu \mathrm{L} 2.5 \mathrm{mmol} \mathrm{L}^{-1}$ dNTPs, $0.8 \mu \mathrm{L}$ each primer $\left(5 \mu \mathrm{mol} \mathrm{L}^{-1}\right), 0.4 \mu \mathrm{L}$ FastPfu Polymerase, and $10 \mathrm{ng}$ template DNA.

Illumina MiSeq sequencing. The amplified DNA was subjected to agarose gel electrophoresis. Then, the amplicons were extracted from $2 \%$ agarose gels and purified with an AxyPrep DNA Gel Extraction Kit (Axygen Biosciences, Union City, California, USA) according to the manufacturer's instructions and quantified using QuantiFluo -ST (Promega, Madison, Wisconsin, USA). The purified amplicons were pooled in approximately equimolar concentrations and were then used for Illumina paired-end sequencing $(2 \times 250)$ according to the standard protocols. The raw sequencing reads were deposited into the National Center for Biotechnology Information (NCBI) Sequence Read Archive (SRA) database.

Illumina data analysis. The Illumina sequences were quality filtered using the default pipeline in QIIME (v. 1.17) by the following criteria (Caporaso et al., 2010): (i) The reads were truncated at positions in an average quality score $<20$ over a 10-bp sliding window, and the truncated reads that were shorter than 50 bp were discarded; (ii) sequences with two nucleotide mismatches in the primer and reads with ambiguous bases were removed; (iii) only sequences that overlap longer than $10 \mathrm{bp}$ were assembled according to their overlap sequence, and reads which could not be assembled were discarded. The assembled reads shorter than $300 \mathrm{bp}$ were eliminated. Fungal sequences were clustered into the operational taxonomic units (OTUs) with a $97 \%$ identity threshold, and OTUs were chosen using the UPARSE pipeline (Edgar, 2013). Chimeric sequences were identified and removed using UCHIME. Furthermore, rarefaction curves and other OTUs-based analyses such as the abundance-based coverage estimators (ACE) and Chao1, Shannon-Wiener index $\left(\mathrm{H}^{\prime}\right)$, and Simpson's index (D) were conducted with the mothur software package.
Chao1 and ACE was calculated to estimate the fungal community richness based on sequence dissimilarity. The diversity within each individual sample was estimated using $\mathrm{H}^{\prime}$ and D (Lim et al., 2010).

\section{Statistical analysis}

Statistical analyses were performed using SAS Version 8.02 (SAS Institute, Cary, North Carolina, USA). All values were expressed as means $\pm \mathrm{SD}(n=3)$. To evaluate differences in fungal diversity, edaphic characteristics, and plant properties at three fertilizer regimes, a one-way ANOVA was analyzed. Duncan's multiple range test was applied when the oneway ANOVA showed obvious differences $(P<0.05)$. To better compare fungal community similarities, Principal Coordinates Analysis (PCoA) was also performed based on Bray-Curtis similarity distance. In addition, the similarities and differences among the communities were described using the number of shared and unique OTUs in the three treatments by a Venn diagram. To compare the top 10 classified phyla and 50 classified genera, a heatmap analysis was performed, and the results were plotted in RStudio using the pheatmap package. A heatmap of correlations between the relative abundances of fungal taxa and edaphic characteristics (e.g. pH, SOC, total $\mathrm{N}$ and soil textures) was tested using the Canoco software for Windows Version 4.5. The histogram was created using Microsoft Excel 2010 (Microsoft, Redmond, Washington, USA).

\section{RESULTS}

\section{Soil physicochemical properties, growth and yield of tea plants}

Soil physicochemical properties including $\mathrm{pH}$, moisture, SOC, and TN, plant height, and tea yield were all significantly $(P<0.05)$ higher in the IF treatment than those in the CK- and CF-treatments, and these soil and plant properties were nonsignificantly $(P<0.05)$ different between $\mathrm{CK}$ and $\mathrm{CF}$ treatments (Table 2). In addition, clay and silt content in the IF treatment increased, but sand content decreased as compared to those of the other two treatments (Table 2). Therefore, differences in soil texture between treatments indicate that the treatment effects may be complexed by variation in soil texture.

Soil fungal community richness and diversity associated with different fertilizer regimes

Based on $97 \%$ sequence identity, this resulted in 143, 129,

Table 2. Soil physicochemical properties, plant heights, and tea yields under different fertilizer regimes in tea plantations.

\begin{tabular}{|c|c|c|c|c|c|c|c|c|c|}
\hline \multirow[b]{2}{*}{ Treatments } & \multirow{2}{*}{$\begin{array}{c}\text { Soil } \\
\text { moisture }\end{array}$} & \multirow{2}{*}{$\begin{array}{c}\mathrm{pH} \\
\left(\mathrm{H}_{2} \mathrm{O}\right)\end{array}$} & \multirow[b]{2}{*}{$\mathrm{SOC}$} & \multirow[b]{2}{*}{$\mathrm{TN}$} & \multicolumn{3}{|c|}{ Soil texture } & \multirow[b]{2}{*}{ Plant height } & \multirow[b]{2}{*}{ Tea yield } \\
\hline & & & & & Sand & Silt & Clay & & \\
\hline \multicolumn{3}{|c|}{$\mathrm{g} \mathrm{kg}^{-1}$} & \multicolumn{2}{|c|}{$\mathrm{g} \mathrm{kg}^{-1}$} & 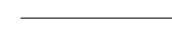 & $\%$ & & $\mathrm{~cm}$ & $\mathrm{~kg} \mathrm{ha}^{-1} \mathrm{yr}^{-1}$ \\
\hline CK & $236.63 \pm 13.11 b$ & $5.40 \pm 0.07 b$ & $5.77 \pm 1.93 b$ & $0.51 \pm 0.15 b$ & $66.15 \pm 2.47 a$ & $2.60 \pm 1.27 \mathrm{a}$ & $31.25 \pm 1.20 \mathrm{a}$ & $75.33 \pm 7.09 b$ & $2637.36 \pm 113.97 b$ \\
\hline $\mathrm{CF}$ & $243.06 \pm 7.29 b$ & $5.20 \pm 0.00 b$ & $6.44 \pm 1.56 b$ & $0.57 \pm 0.13 b$ & $64.35 \pm 2.62 \mathrm{ab}$ & $2.65 \pm 1.06 \mathrm{a}$ & $33.00 \pm 3.68 \mathrm{a}$ & $84.00 \pm 1.71 b$ & $3388.28 \pm 77.70 b$ \\
\hline IF & $284.42 \pm 10.71 \mathrm{a}$ & $6.00 \pm 0.57 \mathrm{a}$ & $10.99 \pm 1.76 \mathrm{a}$ & $1.00 \pm 0.15 a$ & $59.50 \pm 6.93 b$ & $4.25 \pm 1.06 \mathrm{a}$ & $36.25 \pm 5.87 \mathrm{a}$ & $121.00 \pm 12.53 \mathrm{a}$ & $5000.00 \pm 62.16 a$ \\
\hline
\end{tabular}

Values (means $\pm \mathrm{SD}, n=3$ ) with different lower-case letters in a column are significantly different at $P<0.05$ according to the Duncan test.

CK: Non-fertilizers; CF: chemical fertilizers; IF: half-chemical fertilizers plus half-poultry manure plus legume residue; SOC: soil organic C; TN: total N. 
and 145 OTUs in the soil samples under the IF, CF and CK treatments, respectively (Figure 3b). Of the total 182 OTUs, 102 of fungal OTUs were shared among the three treated soil samples (Figure 3b). Moreover, high query coverage $(>99.97 \%)$ indicated that fungal OTUs of each soil sample were well captured (Table 3). All of rarefaction curves of fungal $18 \mathrm{~S}$ rRNA sequences in soil samples reached saturation, suggesting that the number of sequence reads was sufficient to represent most of the sequence type (Figure 1a, 1b). Additionally, the rarefaction and ShannonWiener curves were different among treatments, with the CF treatment showing the lowest number of OTUs (Figure 1a). Generally, the CF-treated soils showed the lowest richness indexes (Chao1 and ACE), while the IF-treated soils had the highest richness indexes (Table 3). Meanwhile, we also found that many of the diversity indices were not significantly $(P<0.05)$ different between treatments (Figure 1b), suggesting the differences are just natural variation in the experimental plots.

\section{Composition of soil fungal communities associated with different fertilizer regimes}

The classified sequences for each treatment were affiliated with the predominant fungal phyla: Ascomycota, Basidiomycota, Zygomycota, Glomeromycota, and Chytridiomycota; the remaining sequences were unclassified fungi and other classified fungal phyla (Figure 2a). Among them, Ascomycota is the largest phylum, and the main genus was Fusarium in soils from subtropical tea plantations, particularly in the IF treatment (Figure 2a). Aside from Fusarium, we also found that the genera Incertae sedis dominated in tea plantations (Figure 2b). Furthermore, samples clustered tightly in each treatment except for CK1 using PCoA of the UniFrac metric matrix. In addition, there were structural similarities between fungal communities from CK2, 3 and those from CF1, 2, 3 treatments, but they were different from those in the IF treatments (Figure 3a). A total $51.77 \%$ of the variations in the composition of fungal communities could be explained by the first two principal components (Figure 3a).

Correlation between composition of fungal communities and soil physicochemical properties

A heatmap for the analysis of the Pearson correlation between the abundance of fungal communities and soil physicochemical properties showed that the abundances of two fungal phyla Ascomycota and Cryptomycota were significantly $(P<0.05)$ positively correlated with edaphic parameters ( $\mathrm{pH}, \mathrm{SM}, \mathrm{SOC}$, and TN concentrations) (Figure 4a). The relative abundance of the fungal phylum Basidiomycota was significantly $(P<0.05)$ negatively correlated with TN, SOC and SM and positively correlated

Table 3. Fungal richness and diversity under different fertilizer regimes in tea plantations.

\begin{tabular}{lccc}
\hline Treatments & CK & CF & IF \\
\hline Reads & 39757 & 39757 & 39757 \\
OTUs & $105 \pm 24$ & $97 \pm 2$ & $104 \pm 3$ \\
Coverage & $0.9998 \pm 0.1020$ & $0.9998 \pm 0.3819$ & $0.9997 \pm 0.7681$ \\
ACE & $109 \pm 25 \mathrm{a}$ & $101 \pm 1 \mathrm{a}$ & $110 \pm 5 \mathrm{a}$ \\
Chao1 & $110 \pm 26 \mathrm{a}$ & $101 \pm 2 \mathrm{a}$ & $115 \pm 7 \mathrm{a}$ \\
Shannon (H') & $2.73 \pm 0.30 \mathrm{a}$ & $2.83 \pm 0.08 \mathrm{a}$ & $2.44 \pm 0.27 \mathrm{a}$ \\
Simpson (D) & $0.1293 \pm 0.0505 \mathrm{a}$ & $0.1052 \pm 0.0136 \mathrm{a}$ & $0.1745 \pm 0.0572 \mathrm{a}$ \\
\hline
\end{tabular}

Values (means $\pm \mathrm{SD}, n=3$ ) with different lower-case letters in a column are significantly different at $P<0.05$ according to the Duncan test.

CK: Non-fertilizers; CF: chemical fertilizers; IF: half-chemical fertilizers plus half-poultry manure plus legume residue; OTUs: operational taxonomic units; ACE: abundance-based coverage estimators.

Figure 1. Fungal rarefaction (a) and Shannon-Wiener (b) curves for normalized number of reads at a $97 \%$ threshold under different fertilizer regimes.
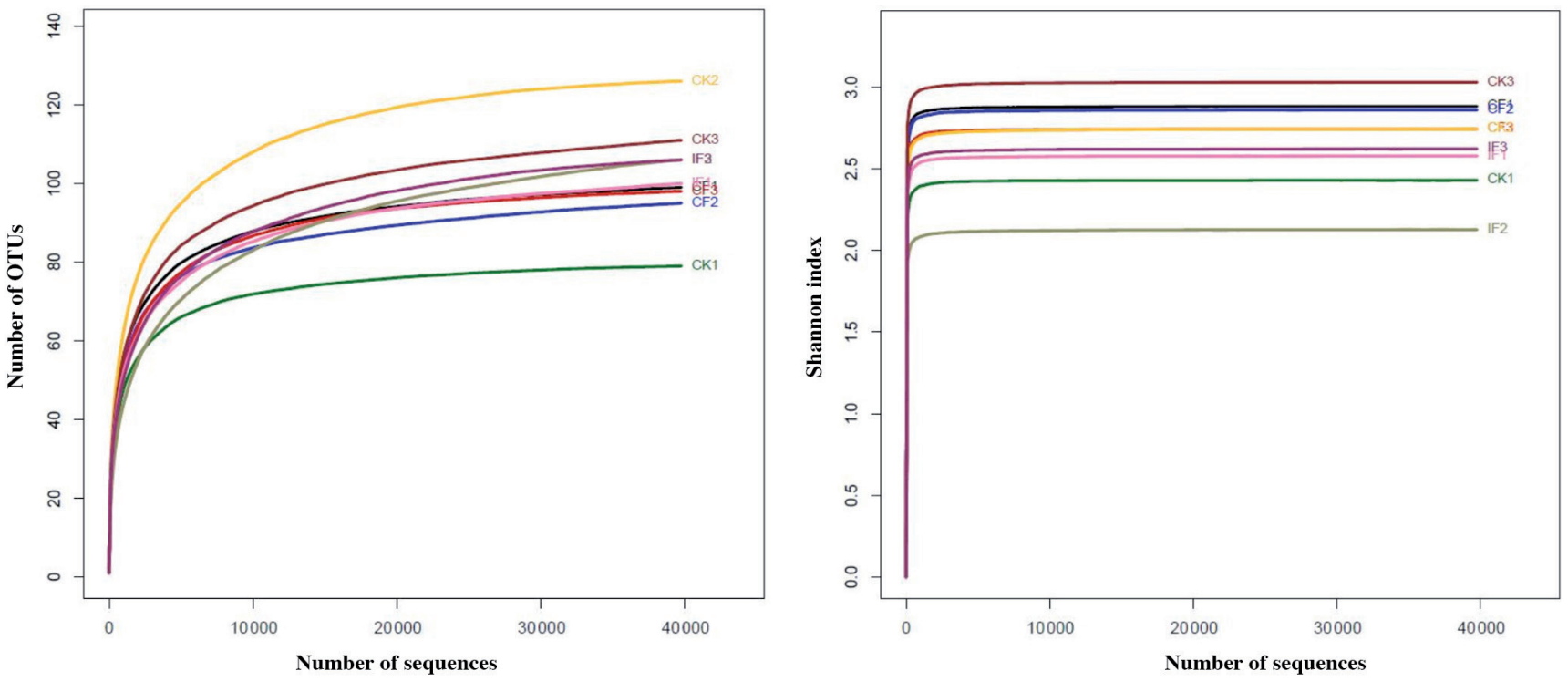

CK: Non-fertilizers; CF: chemical fertilizers; IF: half-chemical fertilizers plus half-poultry manure plus legume residue; OTUs: operational taxonomic units. 
Figure 2. Relative abundances of fungal phyla (a) and genera (b) under different fertilizer regimes.
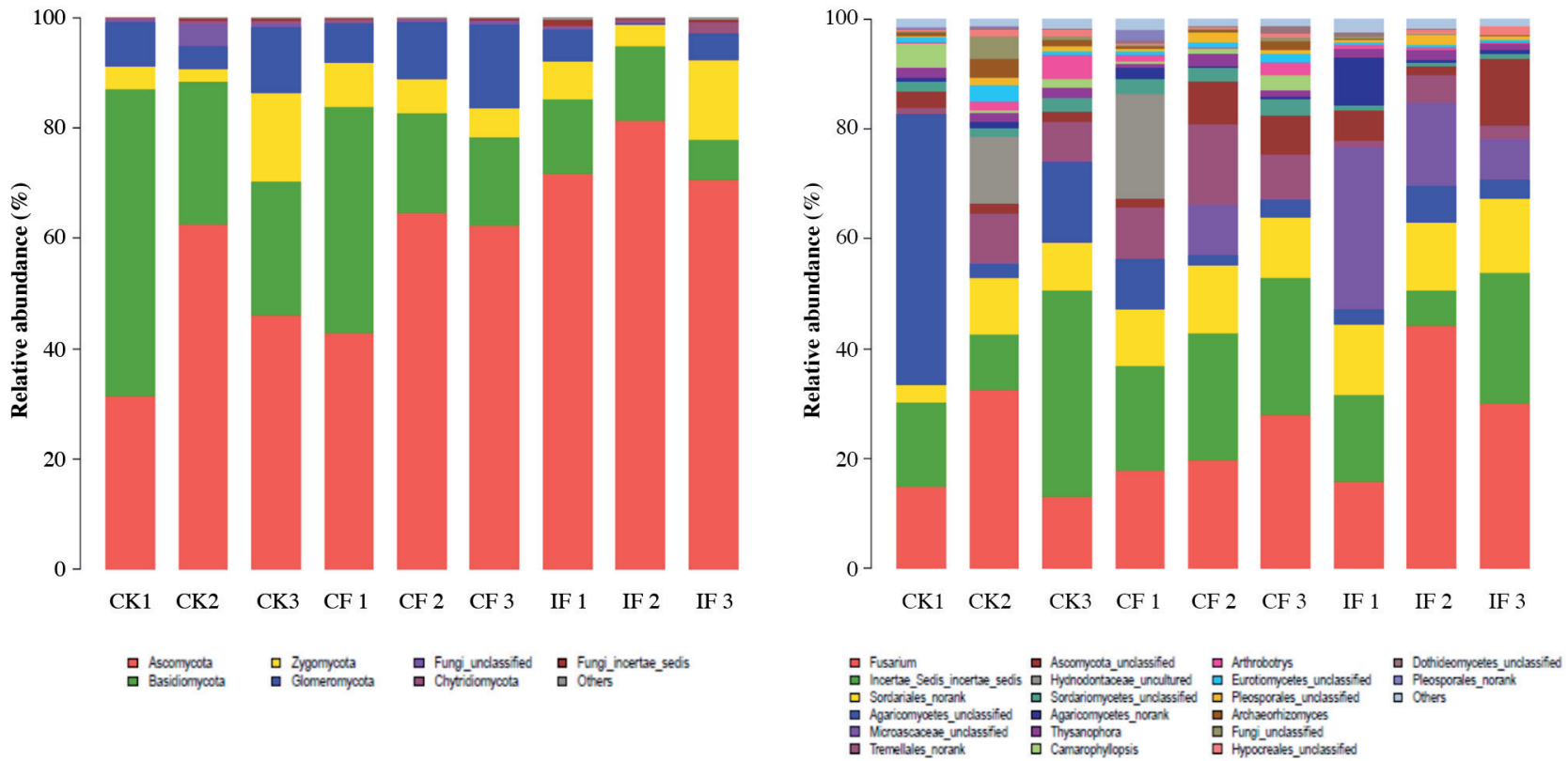

CK: Non-fertilizers; CF: chemical fertilizers; IF: half-chemical fertilizers plus half-poultry manure plus legume residue.

with sand (SA) content in soil (Figure 4a). In addition, there were significant $(P<0.05)$ positive correlations between the relative abundance of the genera Scytinostroma, Leucosporidiales (no rank), Cryptomycota (no rank) and TN, SOC, SM contents, $\mathrm{pH}$, and between the abundance of fungal genera Sordariales (no rank), unclassified Microascaceae and TN, SOC, SM contents, respectively (Figure 4b). Nevertheless, the relative abundance of the fungal genera Camarophyllopsis and unclassified Sordariomycetes showed a significant $(P<0.05)$ negative correlation with TN, SOC, SM, and silt (SI) contents (Figure 4b).

\section{DISCUSSION}

Effect of fertilization on plant heights, tea yields, and soil characters

The CK, CF and IF-treated soils were significantly $(P<$ 0.05 ) different in almost all edaphic parameters (Table 2). Among them, clay content in the IF treatment increased as compared with that of the other two treatments (Table 2). Similar result was reported earlier (Wang et al., 2012). Moreover, the IF, CF and CK treatments increased clay content by $1.34 \%, 11.68 \%$, and $8.70 \%$ in 2016 compared to

Figure 3. Principal coordinates analysis (PCoA) (a) of fungal microbiota based on the unweighted UniFrac distance metric, and the Venn diagram (b) depicts operational taxonomic units (OTUs) that were shared or unique for chemical fertilizers (CF), halfchemical fertilizers plus half-poultry manure plus legume residue (IF), and control (CK).
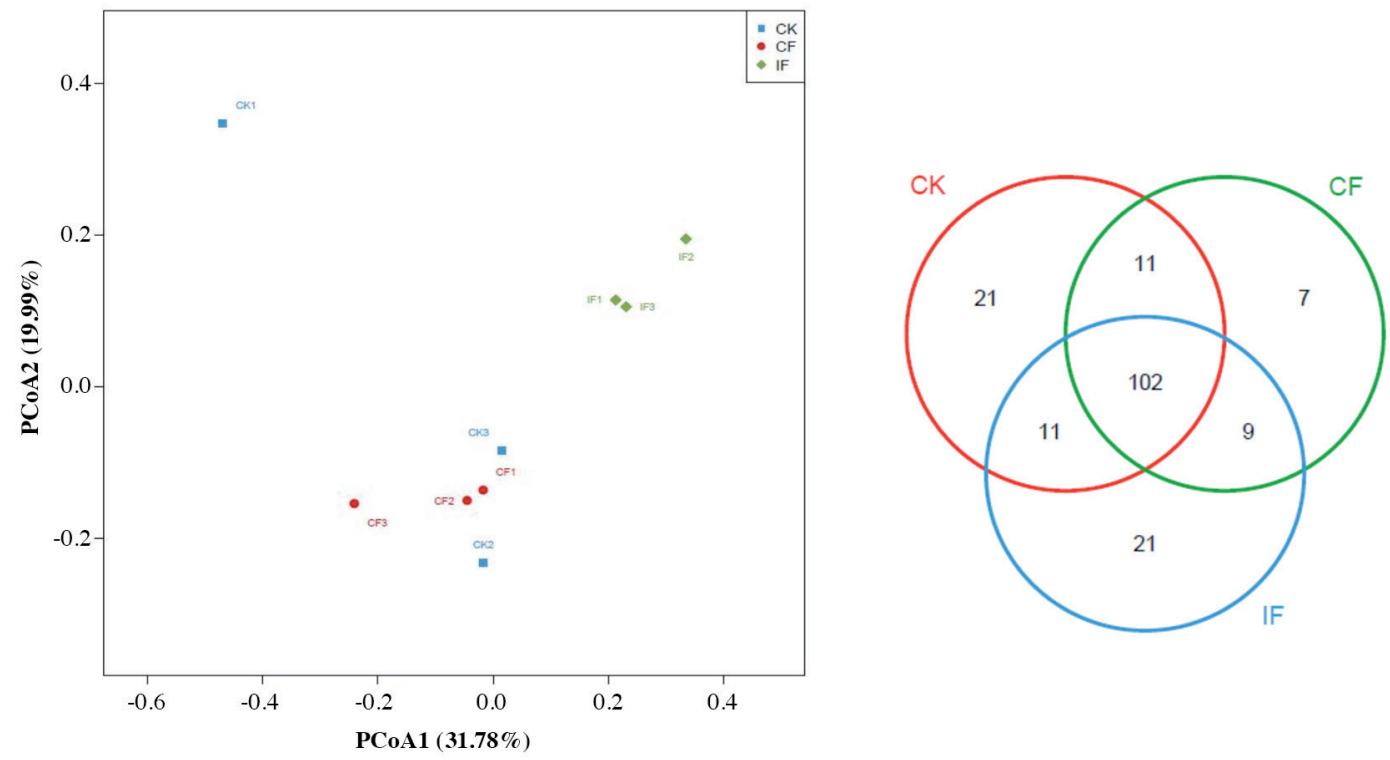
Figure 4. Relationships between soil physicochemical characteristics and the relative abundance of the fungal phyla (a) or genera (b) under different fertilizer regimes.
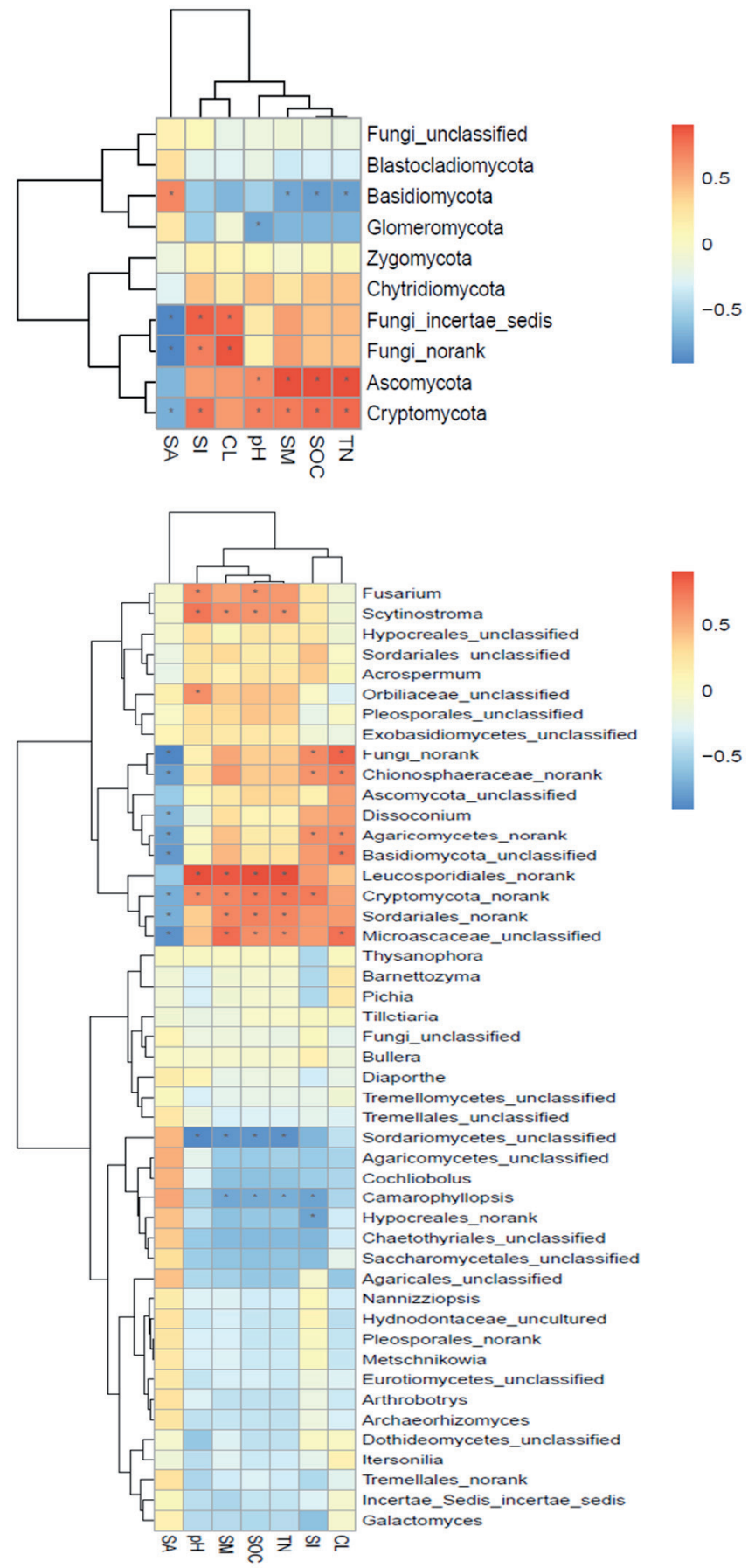

Asterisks denote significant $(P<0.05)$ correlation between fungi communities and corresponding edaphic parameters.

SA: Sand; SI: silt; CL: clay; SM: soil moisture; SOC: soil organic C; TN: total $\mathrm{N}$.

that in 2010, respectively (Wang et al., 2012). The variation in clay content under different fertilization regimes is not only because of fertility variations, but also due to a result of soil forming processes, e.g. allitic process in the red and yellow soil region (Zhao et al., 2017). This process resulted in enrichment of $\mathrm{Fe}$ and $\mathrm{Al}$ oxides, which was helpful to hold clay grains together and to increase clay content (Zhao et al., 2017). Furthermore, Gomes et al. (2016) reported that the preferential partitioning of nutrient elements was in the clay fraction. Taken together, these results suggest that enrichment of nutrient elements in soils could increase with an increase in clay content, which is favorable for fertility promotion of tea soil. In addition, the treated plots were acidic soils, and soil $\mathrm{pH}$ ranged from 5.2 to 6.0 (Table $2)$. Soil $\mathrm{pH}$ was significantly $(P<0.05)$ increased by the combined use of organic manures with chemical fertilizers relative to that of the control treatment, indicating that integrated fertilization with organic and chemical fertilizers could significantly alleviate soil acidification. However, Chen et al. (2016) found that soil pH was nonsignificantly affected after $8 \mathrm{yr}$ of continuous annual organic and chemical fertilizer applications. These inconsistent results can be explained to a large extent by the different types of organic amendments, which would affect $\mathrm{pH}$ levels differently, depending on their quality (Lv et al., 2011). In contrast, the $\mathrm{CF}$ treatment played little role in reducing soil $\mathrm{pH}$. Nevertheless, this result is somewhat in disagreement with Ge et al. (2010), who showed that long-term application of chemical fertilizers significantly decreased soil $\mathrm{pH}$. The major reason for significant acidification in soils with chemical fertilizers is due to acidic $\mathrm{N}$ fertilizer inputs in soils. Meanwhile, higher $\mathrm{pH}$ values for the IF, $\mathrm{CF}$ and $\mathrm{CK}$ treatments than the initial $\mathrm{pH}$ were observed (Table 2), which were mainly induced by addition of alkali metal and alkaline earth metal oxides; these oxides could be created by weathering and leaching of primary aluminosilicates and secondary minerals under hightemperature and high-humidity conditions in the red and yellow soil region after different fertilization over a period of $10 \mathrm{yr}$ in a long-term experiment (Zhao et al., 2017). In general, higher values of SM, SOC, TN, plant height and tea yield were found at IF-treated plots as compared to those at CK- and CF-plots (Table 2), as confirmed in many studies (Lv et al., 2011; Lazcano et al., 2013). Moreover, the cumulative N, P and K obtained from 2008 to 2011 in IF treatment were $4.962 \mathrm{~kg} \mathrm{ha}^{-2}, 0.48 \mathrm{~kg} \mathrm{ha}^{-2}$, and 5.966 $\mathrm{kg} \mathrm{ha}^{-2}$, and significantly $(P<0.05)$ increased by $88.60 \%$, $57.41 \%$, and $98.87 \%$, respectively, compared to those in CK treatment (Lin et al., 2012). These results suggested that the combined application of chemical and organic fertilizers can be exploited for the high and sustainable productivity in acid tea soils.

\section{Effect of fertilization on fungal diversity}

Fungal diversity is not alone for the functions. Furthermore, indices of diversity, which combine species richness and evenness together, also have been called heterogeneity indices. In this study, the number of OTUs, the level of richness (Chaol and ACE), and the value of the Simpson index in the CF treatment were slightly smaller than those of the other two treatments, but differences were nonsignificant 
$(P<0.05)$ (Table 3). This result is in agreement with Chen et al. (2016), who showed that no obvious changes in fungal diversity were found between the use of organic compost combined with CF treatment and CF alone, indicating the relative stability of the fungal community diversity. The reasons for not finding any treatment effects on the diversity measures may be best explained by their response to natural mechanisms rather than by direct effects of fertilization treatments on fungi (McGuire et al., 2012). Climatic factors, followed by spatial patterning, are the best predictors of soil fungal richness and community diversity at the global scale; because climatic variables explained the greatest proportion of richness and community composition in fungal groups by exhibiting both direct and indirect effects through altered soil and floristic variables (Tedersoo et al., 2014). In addition, the host diversity, resource abundance and habitat diversity of tropical systems resulted in an increase in fungal diversity, because increasing the number of plant litter species decomposing on the forest floor would result in greater diversity and abundance of fungal communities (Shi et al., 2014). Moreover, bacterial proliferation following the increase of labile organic substrates had antagonistic effects on fungal growth (Lazcano et al., 2013). Hence, compared to bacterial abundances in soil, the inherently much lower fungal abundance and inhibiting effect of bacteria might be the reasons for nonsignificant differences in fungal diversity between plots with and without organic amendments. Taken together, our findings indicate that different fertilizer treatments have a minor influence on richness and diversity of fungal communities in acid tea soils after $10 \mathrm{yr}$ of fertilization treatments.

\section{Effect of fertilization on fungal community composition}

A total of 182 OTUs were obtained from 357813 qualityfiltered sequence reads with a $97 \%$ similarity threshold at each treatment sites, including representatives of five fungal phyla (Figure 2a). Among them, Ascomycota was the most abundant phylum (60\% of OTUs), followed by Basidiomycota (34\%), whereas the remaining three phyla accounted for a much smaller percentage of the community. Global soil sampling also revealed representatives of all major phyla of fungi; of fungal taxa, the most OTU-rich phyla were the Ascomycota (48.7\%) and Basidiomycota (41.8\%) (Tedersoo et al., 2014), suggesting these two major fungal phyla are ubiquitous throughout most of soil ecosystems. Furthermore, the dominant Ascomycota has been described as lichen-forming fungi, litter/ wood decomposers, plant parasites, endophytes, and saprotrophs (Lim et al., 2010). Meanwhile, the growth rate of Ascomycota is correlated with $\mathrm{N}$ availability, in turn, may dramatically accelerate $\mathrm{C}$ decomposition in soils (Fontaine et al., 2011). In addition, the alkaliphilic trait is spread throughout the Ascomycota (Grum-Grzhimaylo et al., 2016). The other dominant phylum Basidiomycota included ectomycorrhizae and decay organisms of plant residues (Lim et al., 2010). Ectomycorrhizal fungi colonize plant roots and help plants obtain nutrients, such as P, from soil. Decay fungi can decompose hard woody C-rich residues and convert these residues into fungal biomass, carbon dioxide, and organic acids and thus important for $\mathrm{C}$ cycling in soil (Hanson et al., 2008; Fontaine et al., 2011). Compared to the numbers of sequences in the Ascomycota and Basidiomycota, however, fewer sequences of Glomeromycota, Chytridiomycota, and Zygomycota were recovered (Figure 2a). The fungal phylum Zygomycota mineralizes readily available dissolved organic substrates rather than breaking down soil litter polymers (Schmidt et al., 2008), while Chytridiomycota has been reported to infect spores of arbuscular mycorrhizal fungi (Lozupone and Klein, 2002). In this study, the IF treatment caused a dramatic increase in the relative abundance of the most dominant Ascomycota rather than Basidiomycota. In addition, the relative abundance of Glomeromycota differed among treatments, and its relative abundance was the highest in the $\mathrm{CF}$ treatment, followed by $\mathrm{CK}$ and the lowest in the IF treatment. Conversely, a decrease in the abundance of Glomeromycota, resulting from $\mathrm{N}$ fertilizer application, has been reported in long-term field experiments, due to this fungal response to the stimulation of $\mathrm{NH}_{4}{ }^{+}$release by the application of $\mathrm{N}$ fertilizer (Cheng et al., 2012). Likewise, the genera Fusarium and Sordariales (no rank) dominated in IF-treated soils (Figure 2b). Our results indicating the prevalence of Fusarium in subtropical tea plantations are in agreement with the finding of Shen et al. (2015), who reported that Fusarium was the dominant group in the rhizosphere from a different crop, i.e. banana, with quite different soil management practices. Moreover, Fusarium belongs to moderate alkali-tolerant fungi (Grum-Grzhimaylo et al., 2016). The rare genus Camarophyllopsis was only detected at the relative abundances of $0.02 \%$ in the IF treatment (Figure 2b).

PCoA analysis demonstrated that, with the exception of sample CK1, the fungal communities of samples from the three treatments could be divided into two groups (Figure $3 a)$. The CK and CF treatments belonged to one group and the IF treatment was an independent group (Figure $3 a)$. This result is best explained by the fungal response to edaphic variables rather than by direct effects of fertilizer regimes on fungi (Tedersoo et al., 2014). The genera unclassified Microascaceae, unclassified Ascomycota, and Agaricomycetes (no rank) are unique in IF-treated plots and rarely found in other two fertilizer treatments (Figure 2b). These findings were broadly confirmed in arable soils and paddy soils at different sites, respectively (Shen et al., 2015; Chen et al., 2016), indicating that the combined applications of organic manures and chemical fertilizers resulted in the presence of a unique group of fungi in soils. This fungal community structure change may be caused by their responses to variations in soil organic $\mathrm{C}$ and $\mathrm{N}$ contents associated with integrated fertilization (Lazcano et al., 2013; Chen et al., 2016). For example, organic matter (OM) content of 2-1-mm aggregate was related to changes in the composition of soil fungal groups (Guo et al., 2015); accumulation of $\mathrm{OM}$ can promote macroaggregation 
and reduce the effective diffusion of oxygen and then improves microhabitats with effects on fungal community communities (Zhang et al., 2015). Besides, it is likely that the $\mathrm{OM}$ in the integrated fertilization was a $\mathrm{C}$ source for fungal activity, given the dependence of fungal community composition on resource quality and availability. The type of $\mathrm{C}$ input has been found to not only increase the soil fungal biomass but also selected for specific fungal groups, thus alter the fungal community composition (Lazcano et al., 2013). Moreover, the OM addition by the OMIF treatment (inorganic and organic fertilizer applications) has improved aerobic conditions favoring nitrification, and the added $\mathrm{N}$ of the nitrification process generally had negative or neutral effects on OM decomposition, which may have led to the changes in fungal community composition under OMIF treatment (Zhang et al., 2015). In general, these results across different study areas suggested that the fungal communities responded differently to fertilizer treatments, which could result from different effects of plant community dynamics and associated soil characteristics on fungal community composition (Lauber et al., 2008; LeBlanc et al., 2015). First, the change in soil nutrient availability may alter fungal community structure through nutritional resource partitioning (Hanson et al., 2008). Second, the diversity of compounds in plant litter may determine the extent of resource heterogeneity to soil-dwelling fungal decomposer communities, which resulted in corresponding changes in fungal community composition (Grosso et al., 2016). In summary, integrated fertilization practices caused significant changes in fungal community structure in soils, which is the result of complex interactions among selection factors that may favor beneficial or detrimental relationships.

\section{Edaphic factors influencing fungal community structure} The heatmap showed that soil $\mathrm{pH}$ was significantly $(P<$ $0.05)$ positively correlated with the relative abundances of two fungal phyla Ascomycota and Cryptomycota (Figure 4a). This result is in general agreement with previous work that involved different types of soils (Wang et al., 2015). These findings suggested that soil $\mathrm{pH}$ was the most predominant factor responsible for fungal community shifts under different fertilization treatments. Two main mechanisms were suggested to explain $\mathrm{pH}$ effect on fungal community (Zhalnina et al., 2015). The first mechanism explains $\mathrm{pH}$ impact on the fungi by the narrow $\mathrm{pH}$ tolerance of some prokaryotic taxa. Acidification of the interior of a microbial cell inhibits most of the enzymatic activities and of overall cell metabolism. The second mechanism includes $\mathrm{pH}$ mitigation of nutrient availability and ion toxicity in soils. Soil pH was significantly correlated with other soil parameters, such as $\mathrm{C} / \mathrm{N}$ ratio and the concentrations of $\mathrm{NH}_{4}{ }^{+}$and $\mathrm{NO}_{3}{ }^{-}$. This may suggest $\mathrm{pH}$ regulation of the availability of these nutrients (Grum-Grzhimaylo et al., 2016). Addition of chemical fertilizers to Park Grass soil decreases soil $\mathrm{pH}$ through increased nitrification, which causes buildup of soil $\mathrm{C}$, and hence increases $\mathrm{C} / \mathrm{N}$ ratio
(Zhalnina et al., 2015). The $\mathrm{C} / \mathrm{N}$ ratio provides a relative index of nutrient status in the soil and has an indirect effect on the fungal community (Lauber et al., 2008). However, there was conflicting evidence on patterns of fungal diversity and composition along a $\mathrm{pH}$ gradient: soil $\mathrm{pH}$ had a weak effect on fungal diversity (Rousk et al., 2010; Wang et al., 2015). Perhaps the primary reason is that many soil microorganisms have developed adaptive responses to survive in different environments, and these fungi generally exhibit wider $\mathrm{pH}$ ranges for optimal growth (Rousk et al., 2010). In addition to $\mathrm{pH}$, other soil properties such as soil texture and nutrient status also caused the variation in fungal community structure (Lauber et al., 2008; Chen et al., 2016). In this study, the relative abundance of the fungal phylum Basidiomycota was significantly $(P<0.05)$ negatively correlated with TN, SOC and SM contents and positively correlated with the SA content in soil (Figure 4a). This result suggested that the fungal phylum Basidiomycota responded to the long-term integrated fertilization with organic manure and chemical fertilizers, which might result from the effects of high $\mathrm{C}, \mathrm{N}, \mathrm{SM}$ and low SA levels on the composition of fungal communities. Meanwhile, SM, SOC, TN contents were significantly ( $P$ $<0.05)$ positively correlated with the abundances of two fungal phyla Ascomycota and Cryptomycota (Figure 4a). Similar findings were reported by LeBlanc et al. (2015), showing that fungal community richness and structure were strongly influenced by variations in edaphic characteristics, particularly OM contents. Nonetheless, AMF were associated with mineralizable rather than total OM forms. For example, Lazcano et al. (2013) found that the higher presence of readily metabolizable $\mathrm{C}$ in manure appeared to be responsible for the stronger short-term effects on the structure of the soil fungal community, whereas the effects of the more resistant $\mathrm{C}$ forms in vermicompost might be more important for long-term positive effects on soil processes. These treatment effects were not consistent across locations and sampling time points, which were mediated by soil physicochemical properties ( $\mathrm{Lv}$ et al., 2011). Consequently, our results indicate that the changes of the fungal community under IF treatment could be the result of their responses to variations of soil $\mathrm{pH}$, moisture, SOC, $\mathrm{TN}$, and SI contents.

\section{CONCLUSION}

The results of the field experiment revealed that long-term integrated use of chicken manure and legume straw with chemical fertilizers (IF) had larger amounts of organic $\mathrm{C}$ and $\mathrm{N}$ in soils and higher yields of tea as compared to those in the other fertilizer treatments. Moreover, we also showed that IF strongly modified the composition but not the taxon richness and diversity of fungal communities in acid tea soils. Meanwhile, the IF-treated soils had a clear difference in the phylum and genus-level composition of fungi compared with that in the non-fertilization controland chemical fertilizers only-treated soils. The fungal 
phylum Ascomycota and the genus Fusarium were mainly found in the IF treatment. Results of correlation analysis further revealed that soil $\mathrm{pH}$, moisture, soil organic $\mathrm{C}$, total $\mathrm{N}$, and silt were the most influential factors in determining the structure of soil fungal communities under different fertilization treatments. In summary, it is recommended that IF should be utilized to improve soil physical-chemical properties as well as fungal community composition and thus contribute to soil fertility management of tea plantations towards sustainability in the subtropical region.

\section{ACKNOWLEDGEMENTS}

This study was supported by Zhejiang Provincial Key Laboratory of Subtropic Soil and Plant Nutrition, China; grants from the Special Fund of Fundamental Scientific Research at Nonprofit Research Institutions in Fujian (2015R1022-2), the Natural Science Foundation of Fujian Province, China (2011J05057), and National Science and Technology Support Program for $12^{\text {th }}$ Five - Year Plan of China (2015BAD05B01-05).

\section{REFERENCES}

Caporaso, J.G., Kuczynski, J., Stombaugh, J., Bittinger, K., Bushman, F.D., Costello, E.K., et al. 2010. QIIME allows analysis of high-throughput community sequencing data. Nature Methods 7:335-336.

Chen, C., Zhang, J., Lu, M., Qin, C., Chen, Y., Yang, L., et al. 2016. Microbial communities of an arable soil treated for 8 years with organic and inorganic fertilizers. Biology and Fertility of Soils 52:455-467.

Cheng, L., Booker, F.L., Tu, C., Burkey, K.O., Zhou, L., Shew, H.D., et al. 2012. Arbuscular mycorrhizal fungi increase organic carbon decomposition under elevated $\mathrm{CO}_{2}$. Science 337:1084-1087.

Edgar, R.C. 2013. UPARSE: Highly accurate OTU sequences from microbial amplicon reads. Nature Methods 10:996-998.

Feinstein, L.M., Sul, W.J., and Blackwood, C.B. 2009. Assessment of bias associated with incomplete extraction of microbial DNA from soil. Applied and Environmental Microbiology 75:5428-5433.

Fontaine, S., Henault, C., Aamor, A., Bdioui, N., Bloor, J.M.G., Maire, V., et al. 2011. Fungi mediate long term sequestration of carbon and nitrogen in soil through their priming effect. Soil Biology and Biochemistry 43:86-96.

Ge, G.F., Li, Z.J., Fan, F.L., Chu, G.X., Hou, Z.N., and Liang, Y.C. 2010. Soil biological activity and their seasonal variations in response to long-term application of organic and inorganic fertilizers. Plant and Soil 326:31-44.

Gomes, P., Valente, T., Braga, M.A.S., Grande, J.A., and de la Torre, M.L. 2016. Enrichment of trace elements in the clay size fraction of mining soils. Environmental Science and Pollution Research 23:6039-6045.

Grosso, F., Baath, E., and De Nicola, F. 2016. Bacterial and fungal growth on different plant litter in Mediterranean soils: effects of $\mathrm{C} / \mathrm{N}$ ratio and soil $\mathrm{pH}$. Applied Soil Ecology 108:1-7.
Grum-Grzhimaylo, A.A., Georgieva, M.L., Bondarenko, S.A., Debets, A.J.M., and Bilanenko, E.N. 2016. On the diversity of fungi from soda soils. Fungal Diversity 76:27-74.

Guo, L.J., Zhang, Z.S., Wang, D.D., Li, C.F., and Cao, C.G. 2015. Effects of short-term conservation management practices on soil organic carbon fractions and microbial community composition under a rice-wheat rotation system. Biology and Fertility of Soils 51:65-75.

Hanson, C.A., Allison, S.D., Bradford, M.A., Wallenstein, M.D., and Treseder, K.K. 2008. Fungal taxa target different carbon sources in forest soil. Ecosystem 11:1157-1167.

Joergensen, R.G., Mäder, P., and Fliessbach, A. 2010. Long-term effects of organic farming on fungal and bacterial residues in relation to microbial energy metabolism. Biology and Fertility of Soils 46:303-307.

Lal, R. 2000. Environmental soil physics. Soil Science 165:453-454.

Lauber, C.L., Strickland, M.S., Bradford, M.A., and Fierer, N. 2008. The influence of soil properties on the structure of bacterial and fungal communities across land-use types. Soil Biology and Biochemistry 40:2407-2415.

Lazcano, C., Gómez-Brandón, M., Revilla, P., and Domínguez, J. 2013. Short-term effects of organic and inorganic fertilizers on soil microbial community structure and function. Biology and Fertility of Soils 49:723-733.

LeBlanc, N., Kinkel, L.L., and Kistler, H.C. 2015. Soil fungal communities respond to grassland plant community richness and soil edaphics. Microbial Ecology 70:188-195.

Lim, Y.W., Kim, B.K., Kim, C., Jung, H.S., Kim, B., Lee, J., et al. 2010. Assessment of soil fungal communities using pyrosequencing. Journal of Microbiology 48:284-289.

Lin, X.G., Feng, Y.Z., Zhang, H.Y., Chen, R.R., Wang, J.H., Zhang, J.B., et al. 2012. Long-term balanced fertilization decreases arbuscular mycorrhizal fungal diversity in an arable soil in North China revealed by 454 pyrosequencing. Environmental Science and Technology 46:5764-5771.

Lin, X.J., Huang, D.F., Li, W.H., Wang, L.M., Wang, F., Fan, P., et al. 2012. Effect of fertilization regime on tea yield, nutrient accumulation and soil fertility. Chinese Journal of EcoAgriculture 20:151-157.

Lozupone, C.A., and Klein, D.A. 2002. Molecular and cultural assessment of chytrid and Spizellomyces populations in grassland soils. Mycologia 94:411-420.

Lv, M.R., Li, Z.P., Che, Y.P., Han, F.X., and Liu, M. 2011. Soil organic $\mathrm{C}$, nutrients, microbial biomass, and grain yield of rice (Oryza sativa L.) after 18 years of fertilizer application to an infertile paddy soil. Biology and Fertility of Soils 47:777-783.

McGuire, K.L., Fierer, N., Bateman, C., Treseder, K.K., and Turner, B.L. 2012. Fungal community composition in neotropical rain forests: the influence of tree diversity and precipitation. Microbial Ecology 63:804-812.

Paungfoo-Lonhienne, C., Yeoh, Y.K., Kasinadhuni, N.R.P., Lonhienne, T.G., Robinson, N., Hugenholtz, P., et al. 2015. Nitrogen fertilizer dose alters fungal communities in sugarcane soil and rhizosphere. Scientific Reports 5:1-6.

Rousk, J., Baath, E., Brookes, P.C., Lauber, C.L., Lozupone, C., Caporaso, J.G., et al. 2010. Soil bacterial and fungal communities across a $\mathrm{pH}$ gradient in an arable soil. ISME Journal 4:1340-1351. 
Schmidt, S.K., Wilson, K.L., Meyer, A.F., Gebauer, M.M., and King, A.J. 2008. Phylogeny and ecophysiology of opportunistic "snow molds" from a subalpine forest ecosystem. Microbial Ecology 56:681-687.

Shen, Z., Ruan, Y., Chao, X., Zhang, J., Li, R., and Shen, Q. 2015. Rhizosphere microbial community manipulated by 2 years of consecutive biofertilizer application associated with banana Fusarium wilt disease suppression. Biology and Fertility of Soils 51:553-562.

Shi, L.L., Mortimer, P.E., Slik, J.W.F., Zou, X.M., Xu, J.C., Feng, W.T., et al. 2014. Variation in forest soil fungal diversity along a latitudinal gradient. Fungal Diversity 64:305-315.

Tedersoo, L., Bahram, M., Põlme, S., Kõljalg, U., Yorou, N.S., and Wijesundera, R., et al. 2014. Global diversity and geography of soil fungi. Science 346:1078-1088.

Wang, L.M., Lin, X.J., Huang, D.F., Li, W.H., and Qiu, X.X. 2012. Effect of different fertilization patterns on physicochemical properties of red-yellow soil in tea garden. Journal of Northeast Forestry University 40:54-57.

Wang, J.T., Zheng, Y.M., Hu, H.W., Zhang, L.M., Li, J., and He, J.Z. 2015. Soil pH determines the alpha diversity but not beta diversity of soil fungal community along altitude in a typical Tibetan forest ecosystem. Journal of Soils and Sediments 15:1224-1232.
Yu, L., Nicolaisen, M., Larsen, J., and Ravnskov, S. 2013. Organic fertilization alters the community composition of root associated fungi in Pisum sativum. Soil Biology and Biochemistry 58:36-41.

Zhalnina, K., Dias, R., de Quadros, P.D., Davis-Richardson, A., Camargo, F.A.O., Clark, I.M., et al. 2015. Soil pH determines microbial diversity and composition in the park grass experiment. Microbial Ecology 69:395-406.

Zhang, H., Ding, W., Yu, H., and He, X. 2015. Linking organic carbon accumulation to microbial community dynamics in a sandy loam soil: result of 20 years compost and inorganic fertilizers repeated application experiment. Biology and Fertility of Soils 51:137-150.

Zhao, J.S., Chen, S., Hu, R.G., and Li, Y.Y. 2017. Aggregate stability and size distribution of red soils under different land uses integrally regulated by soil organic matter, and iron and aluminum oxides. Soil and Tillage Research 167:73-79. 